\title{
Using GIS for calculating the accessibility to hospitals in the city of Bucharest and its metropolitan area (Romania)
}

\author{
Cristina Merciü*, Daniela Stoian ${ }^{\mathrm{A}}$, George Merciü, Irina Saghin ${ }^{\mathrm{A}}$ \\ Received: September 2013 | Revised: October 2013 | Accepted: December 2013
}

\begin{abstract}
The application of geographical information systems (GIS) to the assessment of accessibility to hospitals has been investigated for an important growth pole in South-East Europe, respectively Bucharest and its metropolitan area. The calculation of accessibility at an intra-regional level is essential, taking into consideration the major role as a capital city, as well as the magnitude of the influence exercised over its hinterland. The territorial dynamics, characterizing a metropolis and also the attraction on a constant number of people, may raise a number of issues such as overcrowding of the main access roads into the city, the pressure put on the public transportation network, the rise of the number of personal cars, which is linked to the longer time needed to travel to various services areas.
\end{abstract}

Key words: transport, accessibility, isochrones, interpolation, Bucharest, Romania

\section{Introduction}

Assuring a high degree of accessibility to essential services (health care facilities, supply and services, cultural and educational, recreational, etc.) is very important especially for the metropolis with high territorial dynamics. In the case of metropolises, the analysis concerns the alternate means of assessing the efficiency of the public transport system with the goal of ensuring improved accessibility for different social categories (pupils and students, employees, elder people). However, for improving efficiently accessibility it is required to identify the obstacles in the urban environment and to evaluate the effect (Svensson, 2010).

Good intra-urban connectivity and accessibility is necessary for ensuring high life quality for all the citizens, a physical and mental health and wellbeing (Tyrväinen, et al., 2007, Sotoudehnia, Comber, 2011) as well as high attractiveness for investments (ESPON GROSEE, Interim Report, 2013).
The relevant recent literature, as well as the EU policies, focus on sustainable urban mobility, improvement of the public transport network and access to services and a better coordination of urban and transport planning (Wickham, Lohan, 1999, Sustainable Urban Transport Plans, 2007, Crampton, et al., 2008, ESPON ATTREG, 2010, ESPON TRACC, 2011).

It is debated whether transport infrastructure improvements contribute to spatial polarization or decentralization (ESPON TRACC, 2013).

In the context of spatial development, the quality of transport infrastructure in terms of capacity, connectivity, travel speeds, etc. determines the locational advantage of an area (i.e. a region, a city or a corridor) relative to other locations, i.e. its competitive advantage (Spiekermann, Wegner, 2007).

The accessibility has both spatial and time features. It displays the convenience degree of a place as a spatial entity. Also, time is the main impedance factor

\footnotetext{
A The Interdisciplinary Center for Advanced Researches on Territorial Dynamics, Faculty of Geography, University of Bucharest, Blvd. Nicolae Balcescu, 1, Bucharest, Romania; krysten1009@yahoo.com

B Faculty of Geography, University of Bucharest, Blvd. Nicolae Balcescu, 1, Bucharest, Romania

* Corresponding author: krysten1009@yahoo.com, fax/phone: 40213138410
} 
of accessibility (Weiping, Chi, 2011). Gulliford et al., 2003 quoted by Higgs (2004) draw a distinction between "having access" to health care and "gaining access", the former may result from the availability of services, the latter refers to whether individuals have the resources to overcome financial, organizational and socio-cultural barriers and utilize that service.

Distance to health care facilities is an important factor for patients, practitioners and administrators (Albert, et al., 200o).

Access to primary healthcare is recognized as an important facilitator of overall population health (Guagliardo, 2004).

Access may be classified according to two dichotomous dimensions (potential vs. revealed, and spatial vs. aspatial) into four categories, such as potential spatial access, potential aspatial access, revealed spatial access, and revealed aspatial access (Khan, 1992 quoted by Wang, 2006). Revealed accessibility focuses on actual use of a service, whereas potential accessibility signifies the probable utilization of a service (Wang, 2006). Spatial access is related to many demographic and socioeconomic variables (Joseph, Phillips, 1984 quoted by Wang, 2006).

The work describes the measurement of accessibility to health services using GIS methods at the level of Bucharest municipality and its metropolitan area.

\section{Methods And Data}

The method of road network accessibility evaluation has been used to calculate accessibility to hospitals. Some of the most common functions of geographic information systems are its measurement functions (Albert, et al., 2000). The authors use ArcGIS to determine the travel time and the distance to the acute hospitals located in the Bucharest municipality. The calculation of accessibility was based on the geometric structure of the public transport network (busses, trams and underground services), walking and cycling networks (Graeme, Aylward, 1999, Parker, Campbell, 1998, Bazemore, et al., 2003, Higgs, 2004, Naphtali, 2006, Kalogirou, Foley, 2006, Svensson, 2010, Weiping, Chi, 2011, Sotoudehnia, Comber, 2011, ESPON TRACC Interim Report, 2013). This calculation was applied to enable travel time and distances for the population from the Bucharest municipality and its metropolitan area.

Bucharest city has the largest transport network in Romania. It is composed of a subway system, plus a surface one consisting of tram, bus and trolleybus.

Also, the accessibility was calculated as a function of the distances between different points in the city and services areas and of the time necessary for these movements (using isochrones). Isochrones maps, showing travel times by public transport from the city centre, were used to assist urban transport planning in the 1950 (Kok 1951, Rowe 1953 quoted by O'Sullivan, et al., 200o). Isochrones were generated using geographic information systems (GIS).

In scientific literature, "access" is mainly measured as a physical distance or travelling time (Sotoudehnia, Comber, 2011).

Also, the Kriging Kernel interpolation calculation and local polynomial interpolation were used. For exact interpolation it was used inverse distance weighted (IDW) method. All these computational models are included in hit maps.

There have been taken into account a series of limitations related to certain rules, imposed in circulation/traffic or by the capacity constraints (road gradients of congestion). It is relatively straightforward to take account of regulation constraints when calculating accessibility. Speed limits can be directly converted to link travel times (ESPON TRACC, Interim Report, 2013). Also, the conditions of the natural environment may sometimes act as obstacles, in terms of access (Merciu, Musat, 2013).

\section{Study Area}

Bucharest is the capital city of Romania gathering according to the last census in 2011 about 1.9 million inhabitants (ISSN, 2011). The capital city has a surface of $238 \mathrm{~km}^{2}$.

The city holds the key administrative, political, economic, educational and cultural activities, attracting daily a considerable number of visitors.

An analysis of the capital city from the point of view of existing facilities in the healthcare sector may lead to the conclusion that most hospitals in Bucharest have benefitted, in the past few years, from an influx of high-end equipment, ensuring the modernization and development of hospitals, ensuring the conditions for improved quality and complexity of medical services. One could mention, among the centers with a tradition in higher education, the Hematology and Medullary Transplant Center at the Fundeni hospital in Bucharest (specializing in oncology). The center has a clinical unit for diagnosis and treatment, the oldest and biggest medical unit of its kind in Romania.

\section{Results}

The basic factor involved in the issue of healthcare access is the spatial distribution of healthcare (supply) and population (demand) (Naghawi, 2012).

There were selected acute hospitals (differentiated by number of beds) of all hospitals in Bucharest, idea supported to highlight accessibility to hospitals and 


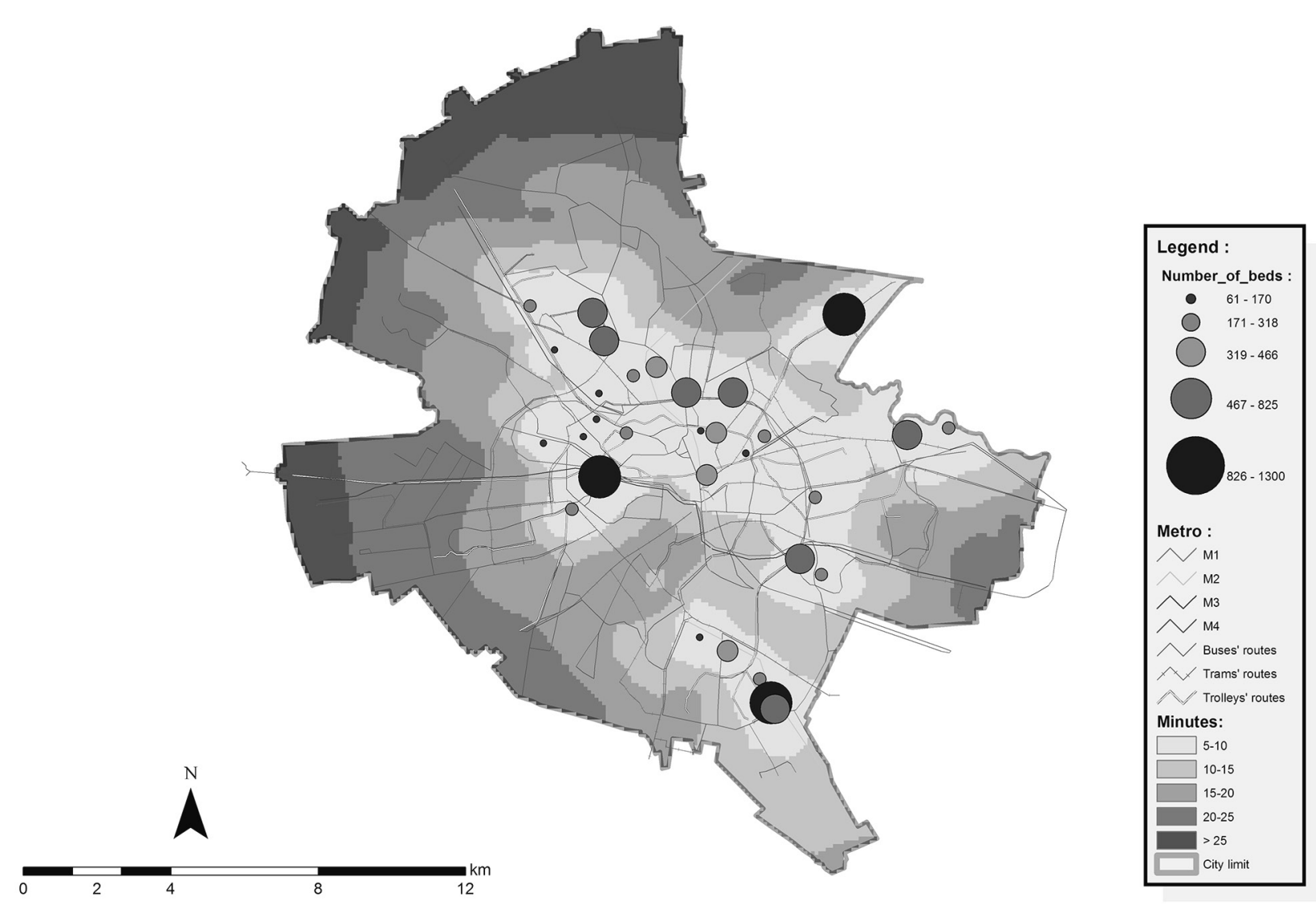

Figure 1. Accessibility to hospitals in Bucharest

of the population that lives outside Bucharest, who seeks medical services of hospitals with certain specialization that are either at a unique national level (eg. Emergency Hospital for Plastic Surgery and Burns). Also, the hospitals from Bucharest are recognized at the national level for the modern facilities and for the quality of professional medical staff.

Analysis shows that the most hospitals in Bucharest are easy accessible for the population especially those located on the central axis and the east-west served by several public transportations means (fig. 1).

Hospitals that present the average accessibility are usually located at the eastern extremity of the city (eg. Fundeni hospital) and southern side (hospital Bagdasar Arseni), these areas being characterized by a lower density of the public transportation network (the existence of at most two forms of transportation or lack of metro area).

Also, the location at the extremities of city hospital units makes it difficult to access them, if patients come from the opposite direction, even using their own vehicles because of the difficulty of crossing a city characterized by heavy traffic.

However, they have the advantage of being more accessible to patients who come from villages located near the capital city, Bucharest being known for attracting a large number of patients from various re- gions of the country to benefit from the competent medical professionals especially for serious diseases; this is the most important medical center of Romania.

A second overview of the situation is meant to indicate the accessibility of the population living inside the metropolitan area to hospitals in the capital city. The differences across the metropolitan area in terms of access to hospitals indicate that a high number of communities, connected to the transport infrastructure (regional roads and highways), are characterized by high and very high accessibility. The localities in Ilfov county (that is, the first two rings of localities surrounding the capital city) may be included in this category (fig. 2).

One can notice that the localities beyond the first two rings, as well, are characterized by high accessibility, as a result of the presence of the A1 (BucharestConstanta) highway transecting the Eastern part of the study area, the $\mathrm{A}_{2}$ (Bucharest-Pitesti) highway in the Western part and the $\mathrm{A}_{3}$ Bucharest-Ploiesti highway to the North.

The localities on the edge of the metropolitan area are located at a relatively big distance from the railway or road networks and they are characterized by limited accessibility (for instance, the villages of Butimanu and Cojasca to the North-West or Greaca, Isvoarele and Hotarele to the South-East) (fig. 2). 


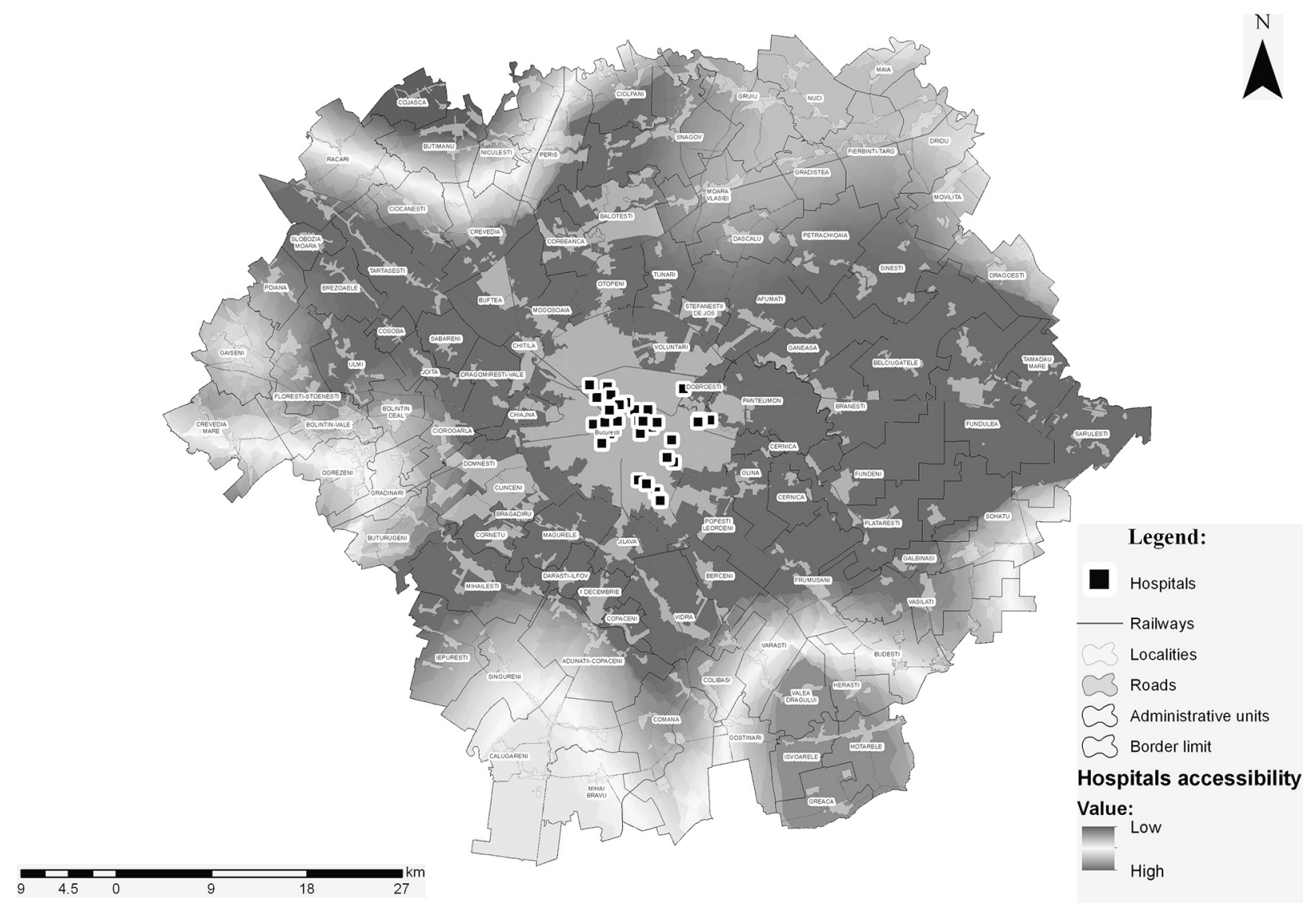

Figure 2. Accessibility of the population from metropolitan area to hospitals in Bucharest

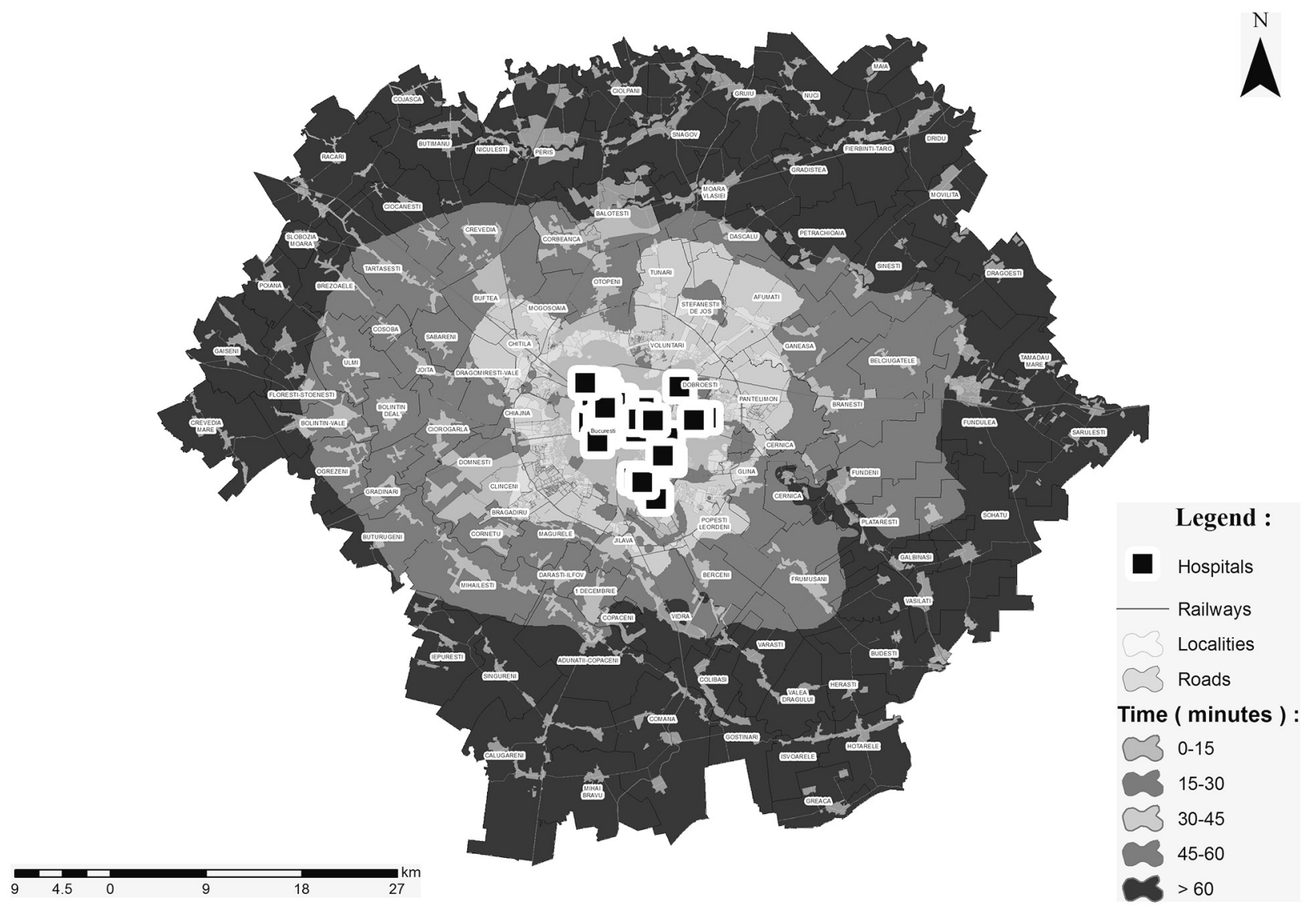

Figure 3. Accessibility (calculated in minutes) of the population from the metropolitan area to the hospitals in Bucharest 


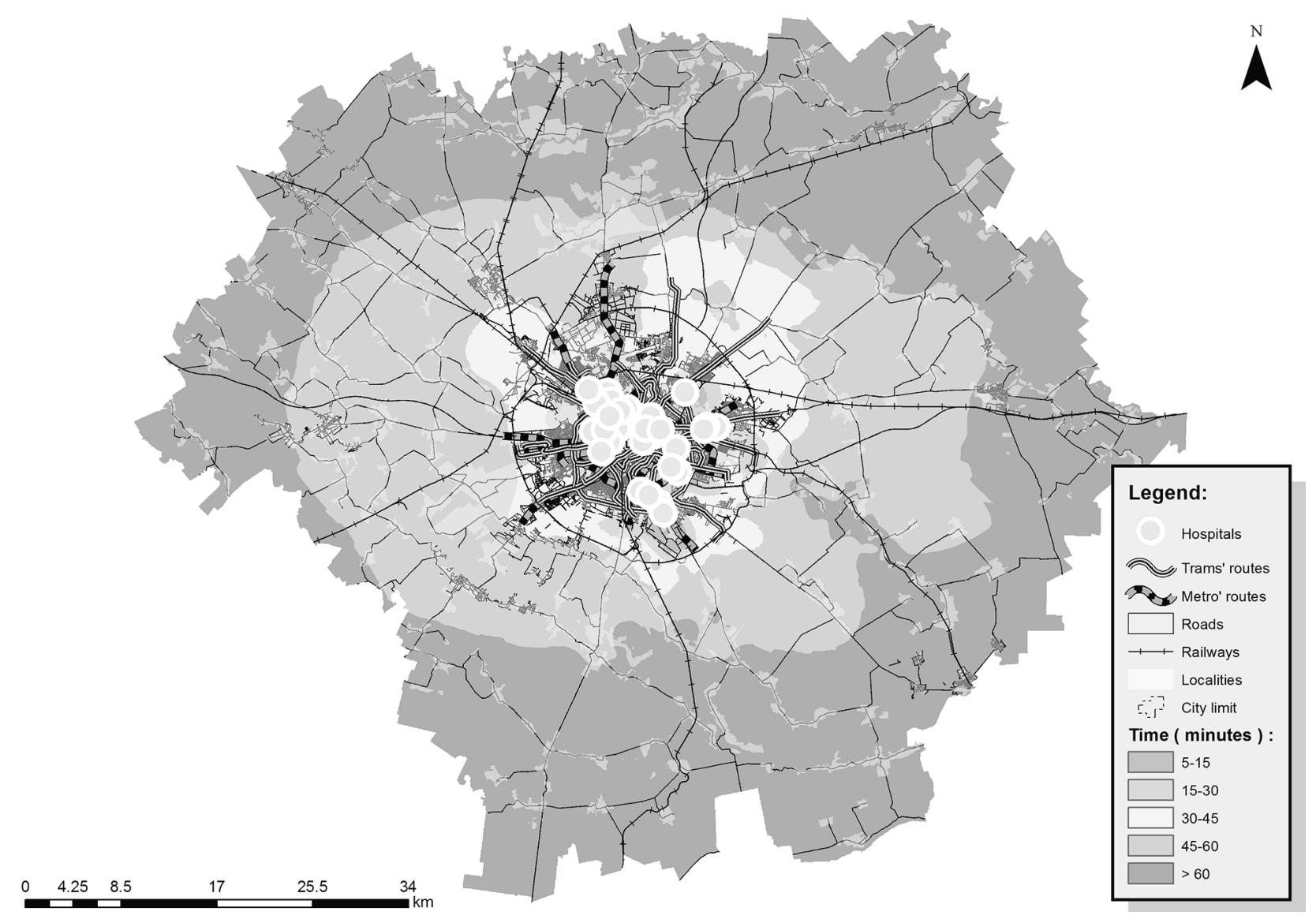

Figure 4. Potential accessibility road by future integrated territorial investments (ITI)

A more accurate representation of the accessibility of the various localities inside the metropolitan area of the city of Bucharest was achieved by means of isochrones and highlighting the time it takes the population to travel from the residence areas to hospitals in Bucharest. One notices that residents in the first ring of localities around Bucharest may travel that distance in 15 minutes; next comes the population in the second ring, with 15-30 minutes needed to travel the distance; the bigger the distance between the localities and the capital city, the longer the time needed to travel the distance: 30-45 and 45-60 minutes respectively, for the central part of the metropolitan area, and more than one hour for the outlying areas (fig. 3).

The authors also calculated potential accessibility of the population in the metropolitan area to the hospitals in Bucharest, taking into consideration the extant public-transport network, the planned subway and tramway lines meant to link the city and the first ring of localities in Ilfov county (fig. 4).

From an organizational point of view, there is a "partnership" between the representatives of the Bucharest City Hall and the members of the Ilfov County Council regarding the common infrastructure projects in terms of transport issues. To this respect, we can mention the integrated territorial investments projects for
Bucharest and its metropolitan area: extensions of the public transport lines from Bucharest to the towns in Ilfov County (extension of the tram lines from $\mathrm{Bu}$ charest to Tunari, Voluntari, Afumați, Gara PopeştiLeordeni, Bragadiru) (Scientific report, ESPON GROSEE, p. 155).

The extension of the metro network is proposed for Bucharest to Otopeni, Mogosoaia-Buftea, Pipera CF Bucharest - Constanta si Berceni - Popesti - Leordeni) (The Development Strategy for Ilfov County "Horizon 2020", 2013). The main scope of this project is to create the intermodal points to increase accessibility for the population and goods, but also to make new proposals related to the alternative transport (extension of the bike lanes).

An analysis of the map of accessibility including the planned subway and tramway line extensions indicates that the accessibility of the metropolitan-area population to the hospitals in Bucharest undergoes limited changes, because the extension of the two transport networks ensures the connection of those localities that already benefitted from good accessibility beforehand.The efficiency of the extension of the subway and tramway lines would have been much greater if the line sections had been longer. For the moment, there are financial limitations to building a bigger subway network, aboveground, than planned. 


\section{Discussions}

Accessibility is not a goal by itself but a derived demand. Accessibility is important because it provides access to opportunities at distant locations or makes it possible to receive goods and services or visitors from distant locations. For policy making, the maximization of accessibility is therefore an objective only as far as it helps to improve the quality of life by facilitating access to opportunities, goods and services and so participation in social and cultural life (ESPON TRACC, Interim Report, 2013).

In the assessment of the effects of accessibility to urban centers, their nature may refer to the economic, social, cultural aspect. Social and cultural effects can be measured and evaluated directly by the availability type indicators during the trip to the urban center, to hospitals, to schools, colleges, universities.

Healthcare accessibility is a vital concern in many societies (Naghawi, 2012).

Ensuring adequate accessibility to medical services turns into a priority not merely in the case of emergencies, but also in the case of people with simple health problems, but who, in the absence of medical services provided on time, may develop more complex problems with considerable discomfort that can be expensive to treat (Haynes, et al., 1999 quoted by Brabyn, Gower, 2003).

The results of the research work conducted enable an identification of the territorial differences across the territory selected, that is the areas well served by the public transport system and benefitting from high accessibility and the areas that are 'under-served' in terms of health facilities.

Although there are numerous studies focusing on the use of GIS applications in the healthcare sector (spatial patterns of disease, analyzing the potential impacts of noxious facilities on trends in morbidity and mortality in local neighborhoods and the use of such tools in emergency planning and ambulance routing, spatial patterns of health services), in general there are few studies dedicated to an overview of the current state of affairs concerning the application of GIS solutions so as to determine the degree of accessibility and identify potential ways of conducting additional research (Hibbs, 2004). An even smaller number of studies focused on the connection between those measures and the overall results on the healthcare sector (Higgs, 2004). From this point of view, a model of accessibility was designed, starting from the suggestion to extend the transport axes that ensure the connection between Bucharest and its metropolitan area so as to observe the effects of an improvement of the public-transport system on the potential accessibility of the population in the metropolitan area to hospitals inside the capital city.
The road network in Bucharest is generally formed on a radial and circular pattern. The city is crossed by nine roads that converge in the city centre (University Square) plus bypass located approximately 3 to $5 \mathrm{~km}$ from the centre. Add the A1 (Bucharest-Pitesti), A2 (Bucharest -Constanta) and $\mathrm{A}_{3}$ (Bucharest-Ploiestirecent time in use) highways and express road Bucharest-Giurgiu. These issues are vital to be mentioned as Bucharest is most important medical center nationally across the country, annually receiving a significant number of patients with various diseases. Road infrastructure that serves the capital city and its metropolitan area plays an essential role in ensuring good accessibility to patients from other parts of the country for the benefit of medical services in different hospitals in the capital city. The health influence area of $\mathrm{Bu}-$ charest is very extended, as a consequence to a number of factors, among which may be mentioned: the importance it has in providing capital quality medical services, technical medical degree and the highly specialized medics, professionals, who work in hospitals.

A major assumption in many studies is that patients will use their nearest health facility; some studies have found that this may not necessarily be the case (Gibbs, 2005).

Referring to the selected case study, one may notice that the trend among the population to travel to the nearest hospital is predominantly found among the residents in rural areas inside the metropolitan area, particularly in the case of mild ailments. In most situations, in rural areas, the patients' preponderantly tending to choosing hospitals nearby reveals the absence of alternative.

However, urban residents inside the metropolitan area choose, to a higher degree, hospitals in the capital city, depending on the hospital specialization, with distance becoming a secondary criterion, especially in the case of more severe ailments.

The studies where GIS technology is used in order to identify the communities who lack adequate access to medical assistance are useful in the sense that they may serve as foundations for local administration's interventions with a view to improving accessibility. In this respect, the decision made at a regional level, concerning the expansion of the public-transport system between the city of Bucharest and the localities inside its metropolitan area may be analyzed from the point of view of the effects it may have on accessibility to hospitals. By extending the subway and tramway lines outwards from Bucharest to the localities in the first ring around the capital city, an alternative is supplied to the extant public-transport system, thus contributing to increased accessibility. However, it should be mentioned that aboveground subway lines might undergo a bigger expansion in the future, so that the 
highest possible number of people would benefit from easy access to medical services.

Information on accessibility could lead to the implementation of development policies that would underlie measures that would solve the shortcomings in the area. At the same time, the respective information offers a big picture that allows for the distinct identification of individual major shortcomings (localities with low accessibility, people without access to private transport opportunities) and the identification of viable solutions whose purpose should be alleviating the dysfunctionalities (identifying those routes where the road network can be developed/expanded).

\section{Conclusion}

The authors have presented an analysis of accessibility to hospitals in Bucharest municipality and its metropolitan area based on GIS spatial analyst methods (Kriging Kernel interpolation).

Based on calculation of various degrees of the population accessibility to health services in Bucharest and its metropolitan area, it reveals a good situation as a result of transportation networks density. Also, this study serves to identify areas poorly served by public transport opportunities. But there may be mentioned a series of malnufunctions related to overcrowded underground network (it is estimated that currently is used by about 600,000 people daily), the transport network is underdeveloped compared to the existing demand.

Related to such matter steps have been taken to extend the metro network, namely the creation of new investments in the west-south-west of the capital and developing connections with the city centre. There can also be mentioned the traffic agglomeration, especially downtown capital due to increased traffic with private cars. This triggers an increase amount of time in the peak hours, to jobs or to get to city center (service area accessed by a large number of people due to their location in a small perimeter).

It can be concluded that the transport plays a vital role in economic and social development and its improvement leads to better reflected accessibility in a shorter access period of time, whether we refer to movements related to profit, health care, recreational domain, cultural side, or educational system.

GIS technology may serve as useful instruments that may underlie political decisions concerning the alleviation of the effects of a less-developed publictransport network on accessibility to hospitals, even more so as there are numerous situations where part of the population does not have access to private transport opportunities. The study is useful to highlighting how the population's accessibility to medical services can be improved. This issue will be detailed in a future work.

\section{Acknowledgement}

This paper was developed with funding from the European Social Fund, in the framework of ESPON GROSSEE Project "Emergence of Growth Poles Network in South-East Europe" - Applied Research 2013/2/19.

\section{References}

Albert, W.M., Gesler W. M., Levergood B. (eds.) 2000. Spatial Analysis, GIS and Remote Sensing Applications in the Health Sciences, Ann Arbor Press, Chelsea, Michigan, $231 \mathrm{pp}$.

Bazemore, A., Phillips, R., Miyoshi, T. 2003. Using Geographic Information Systems to Define Healthcare Access in an Urban Community Health Center Network', ESRI International Health GIS Conference 2003, Arlington, Virginia, May 4-7 2003, available at: http:/gis.esri.com/library/userconf/ healtho3/papers/pap3037/p3037.pdf

Brabyn, L., Gower P. 2003. Mapping accessibility to general practititioners, in: Khan O., Skinner R., (eds.), Geographic information systems and health applications, Idea Group Publishing, Hershey, PA, 289-307 pp.

Crampton, G., Hass-Klau, C., Ferlic, A. 2008. How do public transport investments influence private car ownership?. NahVerkehr 4, 15-21. (in German)

Guagliardo, M. F. 2004. Spatial accessibility of primary care: concepts, methods and challenges. International Journal of Health Geographics 3,3, 1-13.

Graeme, H., Aylward, R. 1999. Using Geographical information system (GIS) to establish access to aged care residential services in non-metropolitan Australia, Proceedings of $5^{\text {th }}$ National Rural Health Conference, Adelaide, South Austrialia, 14-1 $7^{\text {th }}$ March 1999.

Higgs, G. 2004. A literature review of the use of GISbased measures of access to health care services. Health Services \& Outcomes Research Methodology 5, 119-139.

Kalogirou, S., Foley, R. 2006. Health, place and hanly: modeling accessibility to hospitals in Ireland. Irish Geography 39,1, 52-68.

Merciu, G.-L., Musat, S. 2013. Using Geographic Informational System in analysing the healthcare reform's effects on the influx and accessibility of patients from Caraş-Severin to the Reşița County Hospital. Management in Health 17,1, 17-20.

Naghawi, H. 2012. Using information Geografic System in analysing hospital accessibility: a case study in New Orleans. Jordan Journal of Civil Engineering 6,3, 353-360. 
Naphtali, Z. S. 2006. Delivering health-care services to an urban population, in: Maantay J., Ziegler J. (eds.), GIS for urban environment, ESRI Press, Redlands, California, 341-347.

O'Sullivan, D., Morrison, A, Shearer, J. 2000. Using desktop GIS for the investigation of accessibility by public transport: an isochrone approach. Int. J. Geographical Information science 14,1, 85-104.

Parker, E.B., Campbell, J.L. 1998. Measuring access to primary medical care: some examples of the use of geographical information systems. Health \& Place 4,2, 183-193.

Sotoudehnia, F., Comber L. 2011. Measuring perceived accessibility to urban green space: an integration of GIS and participatory map, $14^{\text {th }}$ AGILE Conference on Geographic Information: Advancing Geoinformation Science for a Changing World, April 18-22 2011.

Spiekermann, K., Wegner, M. 2007. Update of selected potential accessibility indicators, Final report, Urban and regional research (S\&W), RRG Spatial Planning and Geoinformation, 29 pp., ESPON Programme, available at: http://www.mdrl.ro/espon_ cd2/Project_Reports/Scientific_briefing_and_networking/MapUpdate_final_report.pdf.

Svensson, J. 2010. Accessibility in urban areas for citizens with impairments: using GIS to map and measure accessibility in swedish cities, in: Maisel, J. L. (ed.), Universal Design: emerging research and developments, Bentham Publishing House, New York, 122-131 pp.

Tyrväinen, L., Mäkinen, K., Schipperijn, J. 2007. Tools for mapping social values of urban woodlands and other green areas. Landscape and Urban Planning 79,1, 5-19.

Wang, F. 2006. Quantitative methods and applications in GIS, Taylor and Francis Group, New York, $304 \mathrm{pp}$.
Weiping, H., Chi, W. 2011. Urban road network accessibility evaluation method based on GIS spatial analysis techniques, Proceedings of the International Archives of the Photogrammetry, Remote Sensing and Spatial Information Sciences Conference $38,2,114-117$.

Wickham, J., Lohan, M. 1999. The social shaping of European urban car systems', Project ScenesusTech: Scenarious for a sustainable society: car transport systems and the sociology of embedded technologies, Employment Research Centre, Dublin, 20 pp.

European Commission. 2007. Sustainable Urban Transport Plans preparatory document in relation to the follow-up of the Thematic Strategy on the Urban Environment, Technical Report, 20 pp.

ESPON ATTREG project (attractiveness of European regions and Cities for Residents and Visitors). 2010. Applied Research 2013/1/7, Final Report, 97 pp.

ESPON GROSSE Project (Growth Poles in SouthEast Europe Emergence of Growth Poles Network in South-East of Europe). 2013. Applied Research 2013/2/19, $52 \mathrm{pp}$

ESPON GROSEE Project. 2013. (Growth Poles in South-East Europe Emergence of Growth Poles Network in South-East of Europe), Applied Research 2013/2/19, Draft Final Report, Interim report, $63 \mathrm{pp}$.

ESPON GROSEE Project (Growth Poles in SouthEast Europe Emergence of Growth Poles Network in South-East of Europe). 2013. Applied Research 2013/2/19, Draft Final Report, Scientific Report, 331 pp.

ESPON TRACC Project (Transport Accessibility at regional-local scale and patterns in Europe), Interim Report Version 21/02/2011, Applied Research 2013/1/10, $164 \mathrm{pp}$.

The Development Strategy for Ilfov County - "Horizon 2020", 2013, $279 \mathrm{pp}$. 